\title{
Research on the Wisdom Education of College English
}

\author{
Jie Xiao ${ }^{1}$, Weimin $\mathrm{Qi}^{*}$ and Qun $\mathrm{Hou}^{2}$ \\ ${ }^{1}$ Department of Foreign Languages, Wenhua College, Wuhan 430074, China; \\ ${ }^{2}$ School of Physics \& Information Engineering, Jianghan University, Wuhan 430074, China. \\ * Corresponding author
}

Keywords: College English; wisdom education; metacognition; information technology.

Abstract. Based on the idea of the wisdom talent cultivation, combined with the information technology and innovation methods in the "Internet plus" era, this paper, guided by the theory of language learning, explores the ways and means of College English wisdom education, hoping not only to improve the students' language learning effect, but also to improve the level of learners' metacognitive strategies and promote the cultivation of the wisdom of language acquisition.

\section{Introduction}

At present, under the educational environment dominated by examination culture, the boundary between "English education" and "English training" is blurred. Thus the following situation happens: Educators are lack of more profound understanding and thinking about the essence and connotation of College English teaching; The role of educators is solidified and their teaching is hard to surpass; Educational ideas are hard to innovate; Educators themselves lack the motivation to advance; educators feel confused about the direction of their development. On the other hand, students still follow the rote learning mode of "imitation- memoryrecitation". Under the pressure of teachers' ''teaching-receiving', learning mode, Students lack the motivation and ability of active learning, lack of personal knowledge generation, and cannot create their own language knowledge system, which leads to low learning efficiency.

The idea of the new curriculum is that the education reform should transcend the simple knowledge education, transcend the single guidance of the examination and the tools, and aim at improving learners' metacognitive strategies and inspiring life wisdom. Step by step education reform should be transformed from training "knowledge people" to cultivating "wise people".

In the Internet plus era, this study explores how the wisdom education promotes the development of learners' metacognition. That is, by means of information technology, the English wisdom education will arouse the vitality of the classroom and lead the teacher's professional growth, let the students create their own language knowledge system, and finally achieve the purpose of improving the metacognitive strategy. This study can not only promote the deep integration of information technology and College English education, but also has a positive significance in exploring the training mode of innovative talents in College English education.

\section{Wisdom Education}

The definition of College English wisdom education: guided by the idea of "creating ideas, creating designs, creating teaching, and creating reflection" and by the theory of language learning, combined with the information technology in the "Internet plus" era, college English wisdom education focuses on how to organize the content of wisdom education in College English class, how to introduce the " integrating creative " wisdom teaching mode into College English education, and how to reconstruct the teaching evaluation mode to make the curriculum evaluation stereoscopic. The purpose of education is to change from the mere knowledge of language to the development of students' language acquisition wisdom, and then achieve the goal of training intelligent talents and improving learners' metacognitive strategies.

Related research at home and abroad: The study of wisdom began at the end of the 1980s. The western theory of wisdom is divided into four schools as follows. 
Table 1 Schools of wisdom theory [1][2]

\begin{tabular}{|l|l|}
\hline Schools & Content \\
\hline $\begin{array}{l}\text { Jean Piaget's cognitive } \\
\text { development theory }\end{array}$ & This theory expounds wisdom from the perspective of cognitive development. \\
\hline $\begin{array}{l}\text { Sternberg' information } \\
\text { processing theory }\end{array}$ & $\begin{array}{l}\text { This theory explores the process and steps of wisdom generation, but lacks the } \\
\text { exposition of the essence and principle of wisdom. }\end{array}$ \\
\hline Snow's theory of learning & $\begin{array}{l}\text { This theory points out that interest in learning is very important for the generation } \\
\text { of wisdom, but lacks the elaboration of the theory of integral intelligence. }\end{array}$ \\
\hline $\begin{array}{l}\text { Jansen's theory of factor } \\
\text { analysis }\end{array}$ & $\begin{array}{l}\text { This theory is mainly aimed at systematic and explicit questions, and lacks the } \\
\text { explanation of the essence and scope of wisdom. }\end{array}$ \\
\hline
\end{tabular}

Entering the twenty-first Century, the concept of "wisdom education" has attracted wide attention from the educational and psychological circles. The research on wisdom education at home and abroad is as follows:

Table 2 Research on "wisdom education"

\begin{tabular}{|c|l|l|}
\hline Time & Researcher & Content \\
\hline 2001 & Sternberg $^{[3]}$ & $\begin{array}{l}\text { He put forward the theory of wisdom balance, discussed the purpose of } \\
\text { wisdom education, and then put forward sixteen principles and six methods of } \\
\text { wisdom education. }\end{array}$ \\
\hline 2000 & Gardner $^{[4]}$ & $\begin{array}{l}\text { He put forward the theory of multiple intelligences, and put forward eight main } \\
\text { intelligence, including linguistic intelligence, logical intelligence and spatial } \\
\text { intelligence etc.. }\end{array}$ \\
\hline 2004 & $\begin{array}{l}\text { Michel Ferrari and } \\
\text { Georges Potworowski } \\
\text { [5] }^{\text {Tingchu Zhang }}\end{array}$ & $\begin{array}{l}\text { He put forward "teaching for wisdom: generation of wisdom from a } \\
\text { cross-cultural perspective". }\end{array}$ \\
\hline 2010 & Changji Li ${ }^{[7]}$ & $\begin{array}{l}\text { He proposed five courses: information, interest, inquiry, intelligence and } \\
\text { intuition. }\end{array}$ \\
\hline 2010 & Guoping Jing & $\begin{array}{l}\text { He put forward the teaching goal of "transforming knowledge into wisdom", } \\
\text { and specifically discussed the necessity of learners' experience and reflection. }\end{array}$ \\
\hline
\end{tabular}

To sum up, scholars have paid more attention to the wisdom education itself, but paid little attention to the combination of intelligence education with a certain course. Especially in the "Internet + " background, there is little research on the integration of College English and wisdom education by using modern information technology. This research is based on the concept of intelligent personnel training, combined with the information technology conditions and innovative research methods in the era of "Internet +", and guided by the theory of language learning, explores the ways and means of College English intelligent education, hoping that this research will not only improve students' language learning effectiveness, but also improve their metacognitive strategies.

\section{Content and Main Forms of Intelligence Education in College English}

Based on the information technology condition and innovation research method, this study explores the implementation of intelligent education in College English curriculum. The goal of College English education is to promote the cultivation of language acquisition wisdom and improve learners' metacognitive strategies.

\subsection{Organize the contents of education reasonably.}

Organize the contents of education reasonably and embody the wisdom of knowledge. Wisdom education pays more attention to the social and intellectual value of knowledge. The content of education starts from three aspects: 
(1). Impart knowledge of objectivity: Teachers should maintain rigorous and logical teaching of basic knowledge, guide learners to self-manage learning, reflect on learning, self-control learning, and guide students to strengthen their ability to understand and remember knowledge.

(2). Understand social knowledge: By imparting the sociality of knowledge teachers cultivate students' wisdom to understand and use knowledge, inspire and guide students to solve problems by creating situational problems, and improve students' ability to deal with practical problems. At the same time, teachers should attach equal importance to the teaching of language knowledge and the input of cultural content, and guide students to open their horizons, experience the culture of the target language and form the thinking mode of the culture of the target language.

(3). Understand Intellectual knowledge: The knowledge imparting in this stage is not based on the specific knowledge points, but on the specific project curriculum to inspire students' wisdom. According to Vygotsky's theory of proximal development area, teachers should take into account the actual situation of students, their current level and potential level, so that the teaching content and progress are in line with the students' recent development zone. Therefore, teachers can adopt the implicit hierarchical teaching method to achieve the goal of teaching stratification, lesson preparation stratification, assignment stratification. Teachers set different teaching objectives to each individual student, and provide students with reference opinions on the use of learning technology resources and the direction and means of dealing with problems. In the process of accomplishing the goal, students need to use knowledge comprehensively, handle practical problems flexibly, enhance the independent consciousness of learning, learn to judge independently, think independently and solve independently, and complete the innovation of learning methods.

\subsection{Introduce the "innovative" intelligent teaching mode into college English teaching.}

Introduce the "innovative" intelligent teaching mode into college English teaching, integrating various teaching organizational forms, and improving the innovativeness of the curriculum.

The "innovative" intelligent teaching mode takes the promotion of wisdom as the core and integrates various means, including the integration of traditional and modern, the integration of students and teachers, the integration of learning and research, the integration of curriculum resources, the integration of teaching methods, so as to achieve the purpose of cultivating ability and enlightening wisdom. The ways to achieve wisdom education in College English teaching are as follows:

(1) The integration of traditional teaching methods and modern teaching methods: Wisdom teaching is not the change of all teaching elements and rules, not the total negation of traditional teaching, but based on traditional teaching, and higher than traditional teaching.

(2) The integration of student centered and teacher led: Teachers should play a leading role in teaching, pay attention to the systematic and objective nature of knowledge imparting, and give full play to the initiative and creativity of learners, reflecting the main role of students in learning.

(3) The integration of curriculum resources from online to offline: Online to Offline, that is, the integration of online and offline curriculum resources. Paper books and teaching materials can no longer satisfy learners' growing knowledge needs. The "Internet +" condition provides more ways to acquire knowledge, including open classes, micro classes, MOOC, flipped classroom, SPOC, mobile APP, software tools, etc. These software resources provide the possibility and technical support for students to study at any time and everywhere. Students can rely on online technology to achieve in-class interaction, foreign language pronunciation training, mobile situational conversation training, language learning electronic portfolio building etc. Relying on the online and offline virtual learning space, teaching can achieve a variety of learning methods, such as reverse interaction, resource sharing and expansion. The integration of curriculum resources can change the traditional single classroom teaching. With more teaching information, more flexible and diverse teaching methods, and more interesting and interactive teaching content, students' interest in learning and learning effect can be effectively promoted.

(4) The integration of teaching methods: Wisdom teaching emphasizes that teachers should adopt the most suitable teaching methods to achieve the optimization of teaching according to different learning objects, teaching contents and learning requirements. In order to achieve individualized and targeted teaching, teachers can adopt implicit hierarchical teaching method, according to the personalized factors of students; 
students can be divided into three levels in the form of internalization. According to the conditions and needs of different levels of students, teachers set different learning goals, implement different guidance strategies, and use multiple formative evaluation methods to meet the learning needs of different levels of students to the greatest extent. [9]

\section{Conclusion}

In a word, College English wisdom education is guided by language learning theory, combined with technological conditions and innovative research methods in the information age, to explore ways and means of wisdom education, hoping to not only improve students' language learning effect, but also improve learners' metacognitive strategies.

\section{Acknowledgment}

This research was financially supported by the Education Science Planning Project of Hubei Province, China (Grant NO. 2017GB146) and by the Project of Wuhan Science and Technology Bureau(Project Number: 2017010201010124).

\section{References}

[1]. Li Yefu, “The Division of the Four Schools of Western Wisdom Theory,” Psychological Development and Education, pp. 61-64, Jan 1996.

[2]. Li Yefu, “Research on Modern Wisdom in China,” Modern Special Education, pp.68-73, June 1996.

[3]. Robert J. S., "Why Schools Should Teach for Wisdom: The Balance Theory of Wisdom in Educational Settings,” EDUCATIONAL PSYCHOLOGIST, vol. 3, pp. 227-245, 2001.

[4]. Howard Gardner, “Multi-dimensional Intelligence,” Beijing: Xinhua Press, vol. 1, pp. 165-175, 2000.

[5]. Michel Ferrari and Georges Potworowski, "Teaching for Wisdom: Cross Cultural Perspectives on Fostering Wisdom”, Springer, vol. 3, pp. 448-456, 2008.

[6]. Tingchu Zhang, “Curriculum and Teaching Philosophy,” Beijing: People's Education Press, vol. 2, pp. 540-561, August 2003.

[7]. Changji Li, “The Mission of Knowledge Teaching: Turn Knowledge into Intelligence,” Tsinghua Journal of Education. vol. 1, pp.48-54, 2010.

[8]. Guo Pingjing, “The intellectual character of Education,” Tsinghua Journal of Education. vol. 2, pp.348-354, 2002.

[9]. Jie Xiao, "Construction of Implicit Hierarchical Teaching of College English under the Guidance of Learning Motivational Strategies,” proceedings of the international conference on Education Science and Education Management. DEStech Publications, Inc, pp.209-214, August 2016. 